\title{
INTERACTION OF ORGANOSILICONE SURFACTANT CONCENTRATION AND SPRAY APPLICATION FACTORS IN GLYPHOSATE EFFICACY
}

\author{
R.E. GASKIN, R.J. MURRAY \\ and J.W. RAY
Plant Protection Chemistry, NZ Forest Research Institute Ltd, P.B. 3020, Rotorua

\begin{abstract}
The interactions between the concentration of an organosilicone, Silwet L-77 ${ }^{\circledR}$ surfactant, and spray application factors were studied. Uptake of spray solutions via stomata and the herbicidal effects of a sub-lethal rate of glyphosate generally increased with increasing Silwet L-77 concentration (0-0.4\%), but the interaction between surfactant concentration and carrier volume (50-800 litres/ha) was highly significant. High surfactant concentrations induced maximal infiltration even at low spray volumes, while low concentrations provided negligible uptake via stomata, except when applied at very high spray volumes. For a constant rate of herbicide, glyphosate efficacy could be accurately predicted by total surfactant dose applied. Fine droplets $(150 \mu \mathrm{m}$ VMD $)$ induced greater infiltration and herbicide efficacy than coarse droplets (300 $\mu \mathrm{m}$ VMD).
\end{abstract}

Keywords: Silwet L-77, surfactant concentration, spray volume, droplet size, glyphosate efficacy

\section{INTRODUCTION}

The superspreading organosilicone surfactants are frequently used as agrichemical adjuvants to enhance the efficacy of pesticides, through improved spray coverage and enhanced uptake into foliage (Stevens 1993; Knoche 1994a). Surfactant concentration is of primary importance in the ability of organosilicones to promote stomatal infiltration of pesticides (Stevens et al. 1991) but little is known about how spray application factors, such as droplet size and carrier volume, can affect this process. The extreme spreading promoted by organosilicones may also result in run-off if spray application parameters are inappropriate (Stevens et al. 1994).

A recent review by Knoche (1994b) highlighted that efficient herbicide application requires a precise definition of spray application parameters. There is a need to understand these to a far greater extent with organosilicones than with conventional adjuvants (Stevens 1993). Accordingly, the interactions between concentration of an organosilicone surfactant and spray carrier volume and droplet size were studied to determine effects on stomatal infiltration and its contribution to efficacy of glyphosate sprays.

\section{Chemicals}

\section{METHODS}

Radiolabelled uptake experiments were conducted with 2-deoxy-D-[U- $\left.{ }^{14} \mathrm{C}\right]$ glucose (Amersham UK), diluted with unlabelled chemical (DOG; $0.72 \mathrm{~kg} / \mathrm{ha}$; Aldrich USA) in carrier volumes of 50-800 litres/ha water. Herbicide efficacy was determined using glyphosate (360 g/l; Roundup $\mathrm{G}^{\mathrm{II}}$, Monsanto NZ) at the sub-lethal rate of $0.108 \mathrm{~kg} / \mathrm{ha}$, in carrier volumes of 50-400 litres/ha. An organosilcone surfactant, Silwet L-77 ${ }^{\circledR}$ (OSi Specialties, NY), was added to spray solutions at concentrations of $0-0.4 \%(\mathrm{w} / \mathrm{v})$. 


\section{Plants}

Field bean (Vicia fabacv. Evergreen) plants were raised in a controlled environment as reported previously (Stevens et al. 1991) and used at 3-4 weeks of age. Tomatoes (Lycopersicum esculentum cv. Russian Red) were raised and used as reported by Ray et al. (1996). Both species have easily wetted, stomatous adaxial leaf surfaces.

\section{Uptake experiments}

Radiolabelled DOG treatments with the addition of Silwet L-77 (0, 0.05, 0.1, 0.2, $0.4 \% \mathrm{w} / \mathrm{v}$ ) were applied to beans with fully open stomata in a controlled environment, as described previously (Gaskin 1995). Droplets ( ca $700 \mu$ m diameter) were applied to individual leaves with a microsyringe, at varying densities per treatment, to approximate field application rates of 50, 100, 200, 400 and 800 litres/ha. At $10 \mathrm{mins}$ after treatment, treated leaves were excised and washed with $2 \times 4 \mathrm{ml}$ water+ethanol $(1+1)$ to recover unabsorbed radiolabel. Stomatal uptake was defined as radiolabel not recovered by washes and calculated as a percentage of the applied dose. Recovery efficiencies of radiolabel from treated plants were $>97 \%$.

\section{Herbicide efficacy experiments}

Glyphosate, at $0.108 \mathrm{~kg} / \mathrm{ha}$, with the addition of Silwet L-77 $(0,0.1,0.2,0.4 \%$ $\mathrm{v} / \mathrm{v}$ ), was applied to tomato plants (8 replicates per treatment) using a tracksprayer (Ray et al. 1996) calibrated to deliver application rates of 50, 200 and 400 litres/ha. Two different nozzles (Spraying Systems NZ) were used; a fine TX 4 ConeJet nozzle delivering droplets with a volume mean diameter (VMD) of $c a 150 \mu \mathrm{m}$ at $300 \mathrm{kPa}$, and a coarse TurboJet 11001 flat fan producing droplets with a VMD of $c a 300 \mu \mathrm{m}(100$ $\mathrm{kPa}$ ). At 10 mins after spraying, plants were thoroughly washed with a fine water spray for 20 secs to remove all unabsorbed herbicide. Heights of all plants were recorded prior to spraying and again at harvest, 14 days after spraying. Plant sizes are expressed as a percentage of unsprayed controls.

All experiments were analysed as factorial designs and treatments were compared using analysis of variance and least significant difference (LSD) tests. Variance stabilising transformations were made where necessary prior to analysis. In addition, surfactant dose/ha (surfactant concentration x carrier volume) was used to model glyphosate efficacy using linear regression techniques.

\section{Uptake}

\section{RESULTS AND DISCUSSION}

The uptake of radiolabel due to spray solutions infiltrating bean stomata increased principally due to organosilicone surfactant concentration (Table 1; Fig. 1A), but the interaction with spray carrier volume was highly significant $(\mathrm{P}<0.0001)$. At the highest surfactant concentration $(0.4 \%)$, approximately $90 \%$ of applied solution infiltrated bean stomata at all carrier volumes (50-800 litres/ha). The lowest concentration of Silwet L-77 (0.05\%) provided minimal uptake, but some infiltration was evident at higher carrier volumes (3200 litres/ha).

Generally, solutions containing low organosilicone concentrations $(<0.2 \%)$ have not been considered capable of substantial stomatal infiltration (Stevens 1993; Buick et al. 1993), despite surface tensions of very dilute Silwet L-77 solutions (ca $0.01 \%)$ being sufficiently low to permit such a process (Ananthapadmanabhan et al. 1990). However, such conclusions have been made with respect to carrier volumes -200 litres/ha (Stevens et al. 1991; Buick et al. 1993). Total organosilicone dose appears to be important in determining stomatal infiltration, and thus, higher application volumes may overcome "adsorptive dilution" effects (Buick et al. 1993) and facilitate substantial uptake via stomata at concentrations $<0.2 \%$. In reality, this may have little practical value because high spray volumes, combined with the excellent spreading properties of organosilicones, may result in unacceptable loss of efficacy due to spray runoff (Stevens et al. 1994).

\section{Spray efficacy}

The effects of surfactant concentration, carrier volume, and additionally, droplet size, were investigated with glyphosate using tomato as a susceptible model plant. Glyphosate performance, in the absence of Silwet L-77, increased as carrier volume 
decreased (Table 1), an effect which is well established for this herbicide (Knoche 1994b). Herbicide efficacy was increased primarily by increasing surfactant concentration, but also with greater carrier volume, and their effects were strongly interrelated $(\mathrm{P}<0.0001)$. By converting all surfactant concentration $\mathrm{x}$ carrier volume data to total organosilicone dose (rate/ha), efficacy was well predicted $\left(R^{2}=0.75\right.$, $\mathrm{P}=0.0002$ ) by the linear model presented in Fig. 1B.

TABLE 1: Uptake of radiolabel at various concentrations of Silwet L-77 and carrier volumes ( $\%$ applied ${ }^{14} \mathrm{C}-$ DOG $^{1}$ into bean), and glyphosate ${ }^{2}$ efficacy (tomato height as percentage of control) due to stomatal infiltration 10 mins after treatment.

\section{L-77 conc.}

(\%)

50

Carrier volume (litres/ha)

(2)

0

0.05

0

0.1

12

0.2

0.4

87

100

200

400

800

$\operatorname{LSD}\left(\mathrm{P}_{0.05}\right)=5.2$

Uptake

(

0
4
18
65
87

0

0.1

0.2

0.4

$\operatorname{LSD}\left(\mathrm{P}_{0.05}\right)=15.8$

\section{0}

45

46

13

\section{Glyphosate efficacy}

$\begin{array}{lrrr}- & 73 & 88 & - \\ - & 51 & 31 & - \\ - & 11 & 10 & - \\ - & 8 & 11 & -\end{array}$

${ }^{1}$ deoxyglucose at $0.72 \mathrm{~kg} / \mathrm{ha} ;{ }^{2}$ glyphosate at $0.108 \mathrm{~kg} / \mathrm{ha}$

A

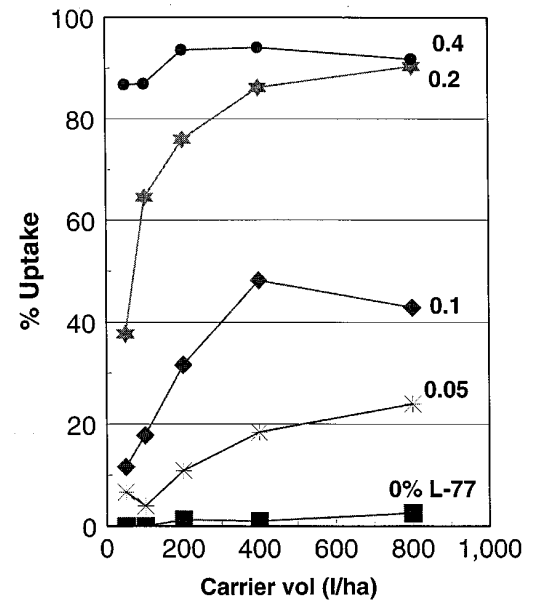

B

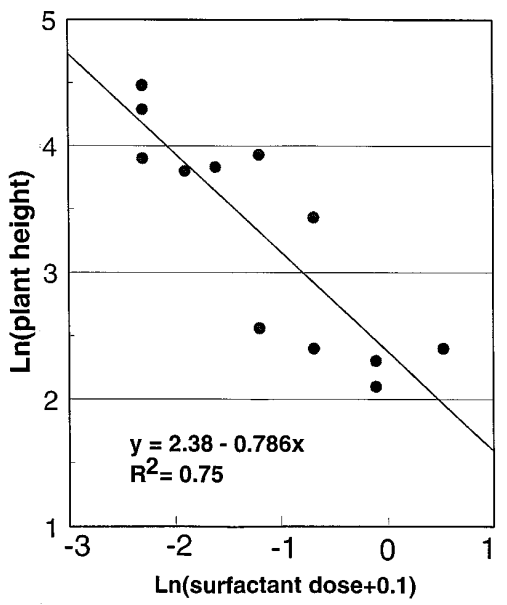

FIGURE 1: (A) Uptake of radiolabel into bean via stomata at a range of organosilicone concentrations and carrier volumes; (B) relationship between surfactant dose (litres/ha) and glyphosate efficacy on tomato. 
Thus, herbicide efficacy, at a constant rate of glyphosate, was directly related to the dose of organosilicone applied to the plant, while the effect of carrier volume was less than surfactant concentration. Such effects on glyphosate activity by Silwet L-77 have been reported previously (Ray et al. 1986). Minor spray runoff from tomato foliage was observed only at the highest spray application volume (400 litres/ha) and organosilicone concentration $(0.4 \%)$, at both droplet sizes. This was reflected only in a very small reduction in efficacy, ie. as a 3\% increase in plant height, (Table 1), and was more evident with fine droplets (Fig. 2).

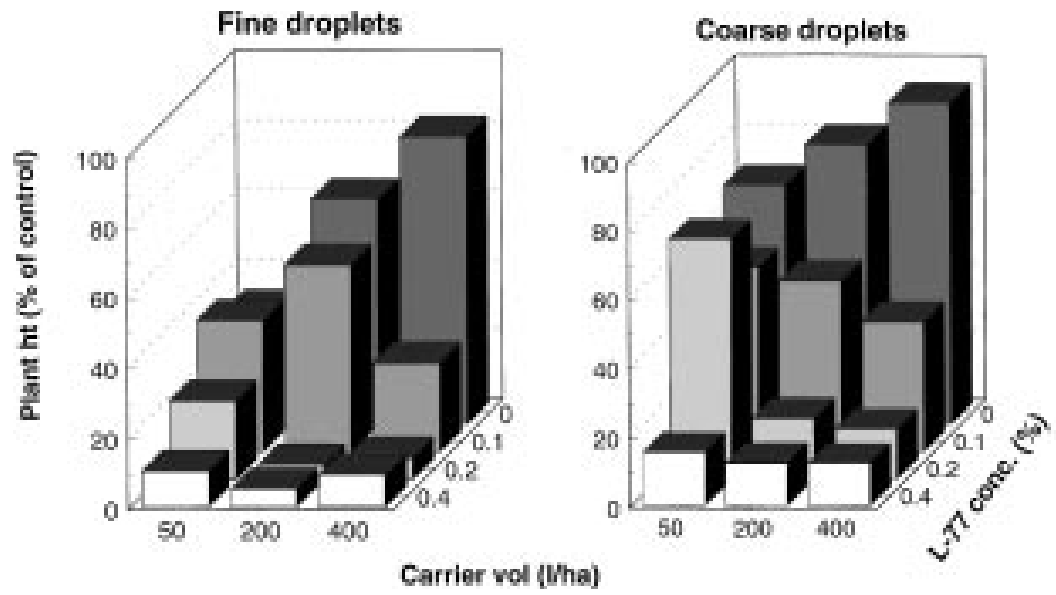

FIGURE 2: Tomato plant height as affected by glyphosate sprays applied as fine and coarse droplets, over a range of carrier volumes and surfactant concentrations $(\mathrm{LSD}=11.2 ; \mathrm{P}=0.05)$

Overall, herbicide performance was improved $(\mathrm{P}<0.01)$ with smaller droplets (Fig. 2). This was most obvious at the lowest carrier volume (50 litres/ha), when fine droplets may have provided better spray coverage. A recent review by Knoche (1994b) suggested that increased coverage, achieved by decreasing droplet size or increasing carrier volume, improves herbicide performance. This may hold true for uptake of glyphosate promoted by low concentrations $(<0.2 \%)$ of organosilicone surfactant, but in this study, there were no benefits in combining high organosilicone concentrations with high carrier volumes or small droplets. Glyphosate efficacy was maximised, with respect to surfactant cost, by application with the highest concentration of Silwet L-77 $(0.4 \%)$ in the lowest carrier volume (50 litres/ha), regardless of droplet size.

\section{CONCLUSIONS}

This study has demonstrated that total dose of surfactant applied is a critical determinant in the efficacy of glyphosate sprays containing an organosilicone. Because of their superspreading and stomatal infiltration properties, the importance of matching organosilicone concentration to carrier volume is far more important than with conventional adjuvants. If spray application factors are not well understood and optimised when using organosilicones, then the full benefits of their use may not be realised.

\section{ACKNOWLEDGEMENTS}

Thanks to Alison Forster and Linda Lester for valuable technical assistance, and to OSi Specialties (USA) for providing chemicals and support. 


\section{REFERENCES}

Ananthapadmanabhan, K.P., Goddard, E.D. and Chandar, P., 1990. A study of the solution, interfacial and wetting properties of silicone surfactants. Colloids and Surfaces 44: 281-97.

Buick, R.D., Buchan, G.D. and Field, R.J., 1993. The role of surface tension of spreading droplets in absorption of a herbicide formulation via leaf stomata. Pesticide Sci. 38: 227-35.

Gaskin, R.E., 1995. Effect of organosilicone surfactants on the foliar uptake of herbicides: Stomatal infiltration versus cuticular penetration. Fourth Int. Symp. Adjuvants for Agrochemicals, FRI Bulletin No. 193: 243-48.

Knoche, M., 1994a. Organosilicone surfactant performance in agricultural spray application: A review. Weed Res. 34: 221-39.

Knoche, M., 1994b. Effect of droplet size and carrier volume on performance of foliage-applied herbicides. Crop Prot. 13 (3): 163-78.

Ray, J.W., Vanner, A.L. and Richardson, B., 1986. Effect of application volume and spray additive concentration on the control of bracken.Proc. 39th N.Z. Plant Prot. Conf: 89-91.

Ray, J.W., Vanner, A.L., Richardson, B. and Coker, G., 1996. Determination of the NOEL of four commonly used forestry herbicides on tomatoes. Proc. 49th N.Z. Plant Prot. Conf:: (this volume).

Stevens, P.J.G., 1993. Organosilicone surfactants as adjuvants for agrochemicals. Pesticide Sci. 38: 103-22.

Stevens, P.J.G., Gaskin, R.E, Hong, S-O and Zabkiewicz, J.A., 1991. Contributions of stomatal infiltration and cuticular penetration to enhancements of foliar uptake by surfactants. Pesticide Sci. 33: 371-82.

Stevens, P.J.G., Walker, J.T.S., Shaw.P.W. and Suckling, D.M., 1994. Organosilicone surfactants: Tools for horticultural crop protection. BCPC-Pests and Diseases: 755-60. 